\title{
Improving the Detection and Tracking of Tropical Cyclones in Atmospheric General Circulation Models
}

\author{
Suzana J. Camargo and Stephen E. Zebiak \\ International Research Institute for Climate Prediction, Lamont-Doherty Earth Observatory of Columbia University, Palisades, New York
}

(Manuscript received 25 February 2002, in final form 10 July 2002)

\begin{abstract}
Dynamical seasonal forecasts of tropical storm frequency require robust and efficient algorithms for detection and tracking of tropical storms in atmospheric general circulation models (AGCMs). Tropical storms are generally detected when dynamic and thermodynamic variables meet specified criteria. Here, it is shown that objectively defined model- and basin-dependent detection criteria improve simulations of tropical storm climatology and interannual variability in low-resolution AGCMs. An improved tracking method provides more realistic tracking and accurate counting of storms.
\end{abstract}

\section{Introduction}

The impact of hurricanes, typhoons, and tropical cyclones on society gives considerable importance to the problem of forecasting seasonal tropical cyclone frequency. Routine seasonal forecasts of tropical storm frequency in the Atlantic sector are produced using statistical methods by Colorado State University (Gray et al. 1993, 1994; Landsea et al. 1994), the Climate Prediction Center of the National Oceanic and Atmospheric Administration (CPC 2002), and the University College of London (UCL 2002). Statistical seasonal forecasts are also issued for the Australian sector and the western North Pacific (Nicholls 1992; Chan et al. 1998). Dynamical forecasting of seasonal hurricane activity using climate models is another promising approach (Bengtsson 2001). Dynamical forecasts of seasonal tropical storm activity are currently produced at the European Centre for Medium-Range Weather Forecasts (ECMWF) based on coupled ocean-atmosphere models (Vitart and Stockdale 2001).

Seasonal prediction of large-scale variables known to affect tropical storm activity is one approach to forecasting tropical storm frequency (Ryan et al. 1992; Watterson et al. 1995; Thorncroft and Pytharoulis 2001). Another method, the subject of this work, is based on the detection of tropical storm and cyclone-like structures in low-resolution atmospheric general circulation models (AGCMs) and coupled ocean-atmospheric mod-

Corresponding author address: Dr. Suzana J. Camargo, International Research Institute for Climate Prediction, Lamont-Doherty Earth Observatory of Columbia University, 225 Monell Bldg., P.O. Box 1000, 61 Rt. 9W, Palisades, NY 10964-8000.

E-mail: suzana@iri.columbia.edu els (Manabe et al. 1970; Bengtsson et al. 1982; Krishnamurti 1988; Krishnamurti et al. 1989; Broccoli and Manabe 1990; Wu and Lau 1992; Haarsma et al. 1993; Bengtsson et al. 1995; Tsutsui and Kasahara 1996; Vitart et al. 1997; Vitart and Stockdale 2001). Some aspects of these model tropical storms, such as their geographical and temporal distributions, have been found to be similar to observed tropical storms. However, the intensity of model tropical storms is weaker, and their spatial scale is larger than observed because of low model resolution (Bengtsson et al. 1982; Vitart et al. 1997).

A fundamental issue is how well tropical storms in AGCM simulations exhibit realistic climatological behavior ("climatology") and interannual variability. Methods for objective detection and tracking of model tropical storms in AGCMs are necessary to investigate this issue. Various tropical storm detection and tracking methods are reviewed in Vitart (1998). These methods monitor when chosen dynamical and thermodynamical variables exceed thresholds determined from observed tropical storm climatologies. Previous studies (Bengtsson et al. 1982; Vitart et al. 1997) used a set of threshold criteria globally. Threshold criteria taken from observational climatological values do not account for model biases and deficiencies. Here, we demonstrate that use of basin- and model-dependent threshold criteria improves the climatology and interannual statistics of model tropical cyclones.

Tracks of tropical storms in AGCMs are usually made by connecting nearby locations that satisfy the model storm detection criteria. Model tropical storms are then defined as those tracks that are longer than some fixed time interval, in most cases 1.5-2.0 days (Bengtsson et 
al. 1995; Vitart et al. 1997). Tracks defined in this manner are shorter than observed storm tracks, because despite the obvious presence of a maximum in the lowlevel vorticity and a minimum in the sea level pressure in the model output, it may not consistently satisfy all of the criteria throughout its lifetime. Such unrealistic tropical storm tracks make landfall studies difficult. Here we introduce a new tracking algorithm that extends tracks of detected storms forward and backward in time using relaxed threshold criteria. A similar idea of relaxing the thresholds for the tracking has been used in a regional climate model for the South Pacific (Nguyen and Walsh 2001). This method allows the identification of the formation and decay stages of model tropical storms, information useful for studying cyclogenesis (Camargo and Sobel 2002). Similar algorithms for tracking synoptic features in AGCMs have been previously developed for extratropical cyclones where cyclone activity is associated with strong variations in the pressure field (Williamson 1981; Treut and Kalnay 1990; Murray and Simmonds 1991; Hodges 1994; Zolina and Gulev 2002).

The new detection and tracking algorithms have been tested with several different AGCMs and found to improve the climatology and interannual variability when compared with previous approaches. The algorithms were also applied to the ECMWF reanalysis dataset ERA-15 (Gibson et al. 1997; Serrano 1997) with similar results.

We begin our discussion in section 2 with the joint statistics of tropical-cyclone-related variables. In section 3 we present the basin- and model-dependent criteria for storm detection and their application to the German T42 ECHAM4.5 model (Roeckner et al. 1996). Section 4 discusses the new tracking method. Conclusions are given in section 5. Details of the algorithms are found in the appendixes.

\section{Joint statistics of tropical-cyclone-related variables}

In the tropical storm detection methods of Vitart et al. (1997) and Bengtsson et al. (1995), tropical storms are identified by first requiring that the $850-\mathrm{hPa}$ relative vorticity; the $10-\mathrm{m}$ wind speed; the temperature at 850 , 700,500 , and $300 \mathrm{hPa}$; and the sea level pressure simultaneously satisfy a set of treshold criteria. Then nearby points are connected and classified as a tropical storm when they span at least 2 days. Criteria details are given in appendix A.

A basin-independent version of this algorithm using the threshold values (basin-independent thresholds) from Vitart et al. (1997) and Bengtsson et al. (1995) was applied to an ensemble of 12 integrations of the ECHAM4.5 AGCM at T42 resolution forced with observed monthly mean sea surface temperatures for the period 1979-95 Atmospheric Model Intercomparison Project II (AMIP II 1997) This resolution is used at the
International Research Institute for Climate Prediction (IRI) for routine seasonal forecasts (Mason et al. 1999; Goddard et al. 2001).

Seven ocean basins were considered following previous studies and are shown in Fig. 1. In basins such as the Atlantic and the eastern Pacific, the detection algorithm using basin-independent thresholds does not detect tropical storms that by subjective visual inspection are evident in different model fields. Visually, these tropical storms appear as extrema in the low-level vorticity, a minimum in surface pressure, a cyclonic circulation in the low-level winds, and a maximum of anomalous temperature throughout the troposphere. Therefore, basin-dependent threshold criteria are a reasonable approach to improving detection algorithms. Also, differences in model behavior mean that thresholds appropriate for one model are not useful for another model, and so threshold criteria should be model dependent.

To obtain robust methods of estimating basin- and model-dependent thresholds we begin by looking at statistical properties of the dynamic and thermodynamic variables used in the detection criteria. Since we require that the criteria be satisfied simultaneously we look at joint probability distribution functions (PDFs). Much of the relevant information can be seen in joint PDFs of lowlevel vorticity/vertically integrated anomalous temperature and low-level vorticity/surface wind speed. The vertically integrated anomalous temperature is defined using three pressure levels throughout the troposphere (see appendix B for definition). The detailed procedure used to calculate the PDFs is also described in appendix B.

In Fig. 2 the joint PDF for the low-level vorticity/ vertically integrated anomalous temperature is shown for the western North Pacific and Atlantic basins based on the ECHAM4.5 model. In Fig. 3 the PDF for the low-level vorticity and the vertically integrated anomalous temperature (Fig. 3a) and surface wind speed (Fig. $3 b)$, respectively, in the western North Pacific basin using ECMWF ERA-15 reanalysis results are given.

The low-level vorticity and vertically integrated anomalous temperature and surface wind speed are normalized in each joint PDF by the corresponding standard deviation in that ocean basin as shown in the PDFs in Figs. 2 and 3. The core portions of these four distributions are quite different. Tropical cyclones correspond to extreme values of all three of our classifying variables and, therefore, occupy a small region on the periphery of the PDF domain. In the joint PDF vorticity/temperature, the tropical cyclones occur for large values of vorticity and positive vertically integrated temperature anomalies. At higher values of vorticity, the joint PDF distribution is such that larger values of the temperature anomalies are expected. In a similar way, the joint PDF vorticity/wind speed distribution features higher vorticity together with higher wind speed. Tropical cyclones have all these characteristics: high vorticity, wind speed, and positive temperature anomalies; so potentially they 


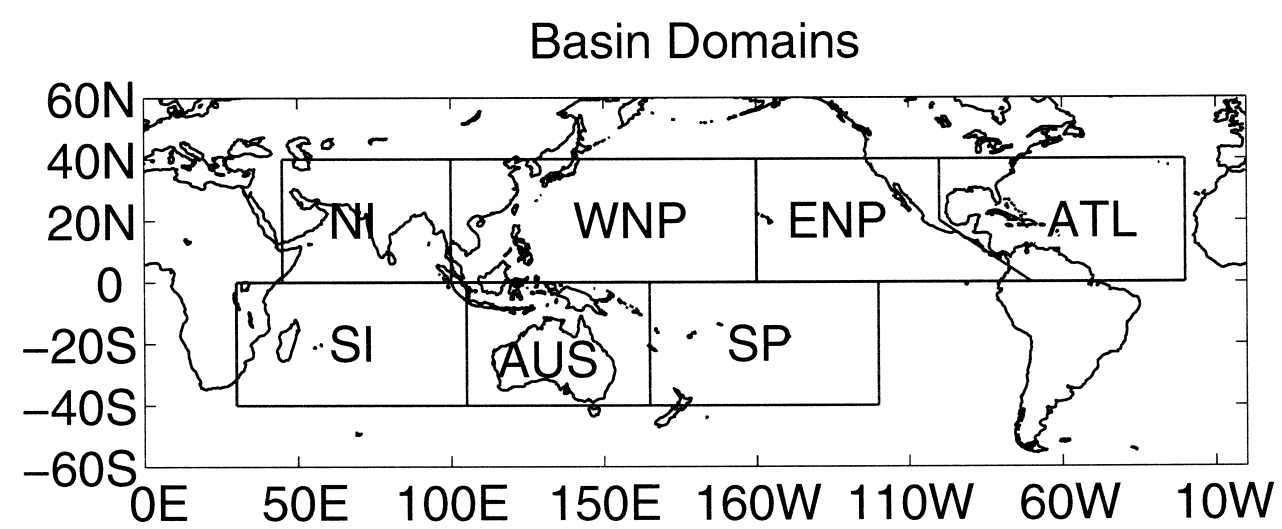

FIG. 1. Definition and location of the basin domains used in this study: north Indian (NI), western North Pacific (WNP), eastern North Pacific (ENP), Atlantic (ATL), south Indian (SI), Australian (AUS), and South Pacific (SP).

can be well represented by appropriate tails of these PDFs. The PDFs are normalized by the total number of storms, so they represent a relative frequency of storms in each basin. The tails of the two distributions in normalized variables in Figs. 2 and 3 are sufficiently similar that it seems reasonable to use a single criterion defined in terms of the normalized variables. Therefore, the idea is to choose threshold criteria so that events in the distribution tails are selected. The PDFs show that modeland basin-dependent criteria are necessary to accomplish this.

Figure 2 shows that the ECHAM4.5 model has very different characteristics in the two basins shown. In the western North Pacific (Fig. 2a) the distribution has a larger spread, with higher peak values of the vorticity, such that with a common threshold would not select the tail of both distributions. We applied the same analysis to two other AGCMs [ECHAM3 (Model User Support Group 1992) and National Aeronautics and Space Administration's (NASA) Seasonal to Interannual Prediction Project (NSIPP) model (Suarez and Takacs 1995)] (not shown) and to the ECMWF reanalysis (Fig. 3), and all the PDFs obtained have similar qualitative features in the models and in the reanalysis. However, the numerical characteristics of the PDFs such as mean, standard deviation, and maximum location are basin and model dependent. This suggests defining the detection criteria in relative terms rather than absolute terms.

Serrano (1997) and Walsh (1997) analyzed the representation of tropical cyclones in high resolution using the ERA-15 reanalysis and ECMWF analysis, respectively. The resolution was an important factor in how well the analysis represented tropical cyclones (Serrano 1997) and even with a resolution of $1.235^{\circ}$ the maximum surface wind speeds of analysis tropical cyclones were much lower than observed. Understandably, with a resolution of $2.5^{\circ}$, the tropical cyclones represented in the ERA-15 reanalysis have even lower surface wind speed and only a handful reach the observational minimum surface wind speed for a hurricane of $17 \mathrm{~m} \mathrm{~s}^{-1}$, which corresponds to $6.5 v / \sigma_{v}$ in Fig. 3b, mainly due to the low resolution of the reanalysis data used.

\section{Detection algorithm}

Our detection algorithm, described in appendix A, applies basin-dependent threshold criteria to three variables: low-level vorticity, surface wind speed, and vertically integrated temperature anomaly. The basin-dependent thresholds should reflect the different statistical characteristics of each variable and model. However, here we emphasize their basin dependency since the results of a single model are described in this paper.

For each of the detection variables, thresholds of the form $\alpha \sigma+\beta$ were defined, where $\alpha$ and $\beta$ are constants independent of the basin, chosen to provide consistency on average with fixed thresholds introduced in prior studies. The standard deviation $\sigma$ of each of these three variables is model and basin dependent. This choice of threshold allows us to have thresholds defined from a single variable $\sigma$ in a form that is consistent with observed and previous studies results, but taking into account the differing basin and model statistics.

The vorticity threshold in each basin $\xi_{\text {min }}$ is defined as $\xi_{\text {min }}=2 \sigma_{\xi}$, that is, twice the vorticity standard deviation $\sigma_{\xi}$ in each basin. The vertically integrated anomalous temperature standard deviation $\sigma_{T}$ was calculated only for systems with a warm core, by analogy to the PDFs in appendix B. The basin-dependent threshold for the vertically integrated anomalous temperature $T_{\min }$ is chosen to be the basin standard deviation, $\sigma_{T}$. Last, in the case of the surface wind speed basin-dependent threshold $v_{\text {min }}$, first the oceanic global wind speed $v_{\mathrm{gl}}$ was calculated - the average wind speed over all the ocean basins, as defined above. Then, using both the wind speed standard deviation in each basin $\sigma_{v}$ and the global average oceanic wind speed $v_{\mathrm{g}}$, the wind speed basin-dependent threshold was defined as $v_{\min }=v_{\mathrm{gl}}+$ $\sigma_{v}$. Threshold values obtained this way are shown in Table 1 together with the basin-independent values used 
(a)
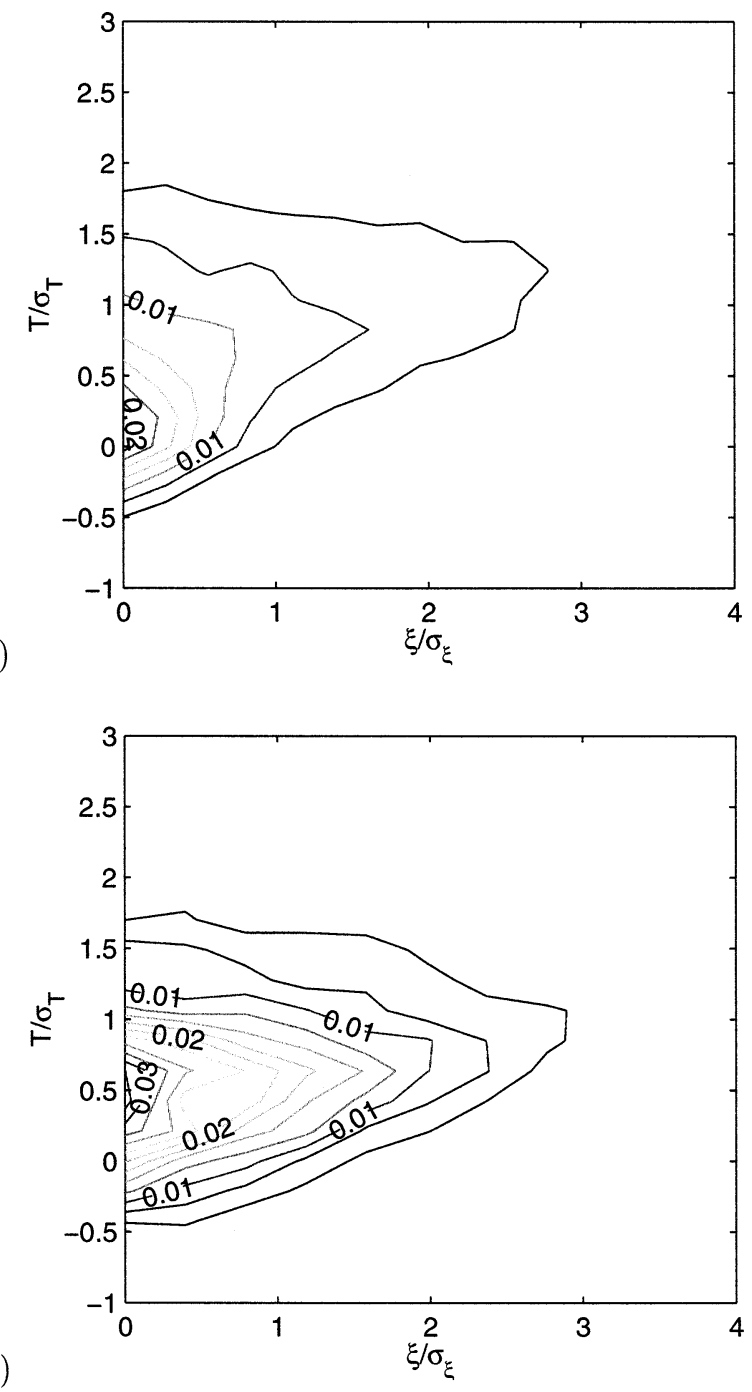

FIG. 2. Joint PDF of the vorticity $\xi$ and vertically integrated temperature anomaly $T$ for (a) the western North Pacific and (b) the Atlantic basins of the ECHAM4.5 model. In (a) and (b) the contour interval is $2 \times 10^{-4}$. The variables are normalized by their respective standard deviation $\sigma$. The $\sigma_{\xi}$ values are, respectively, 1.8 and 1.3, and the $\sigma_{T}$ values are 1.9 and 1.9 in the western North Pacific and Atlantic basins.

in our initial study. We note, for instance, that the thresholds are lower in the Atlantic. These parameter choices were made based on the joint PDFs' statistical properties. The basin-dependent threshold values so chosen are not very different from the basin-independent ones initially used, which were based on observational values

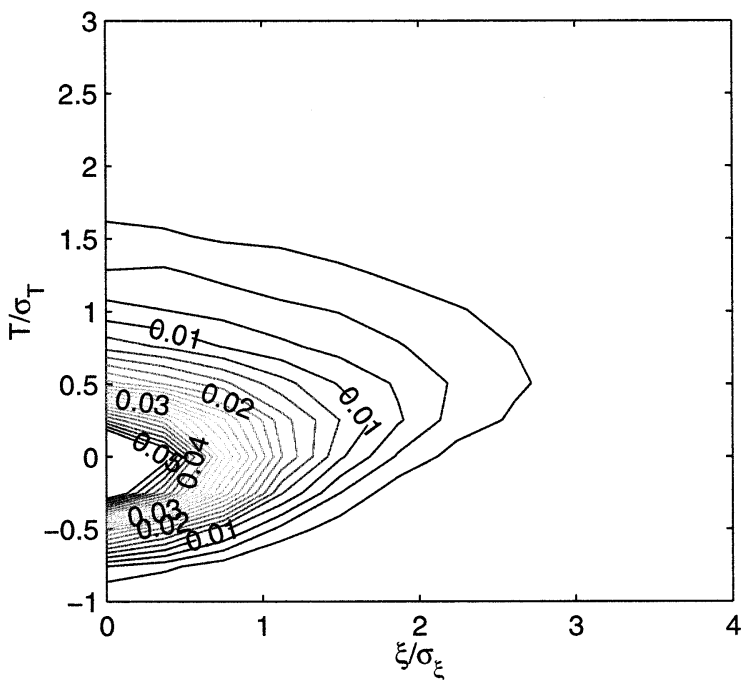

(a)

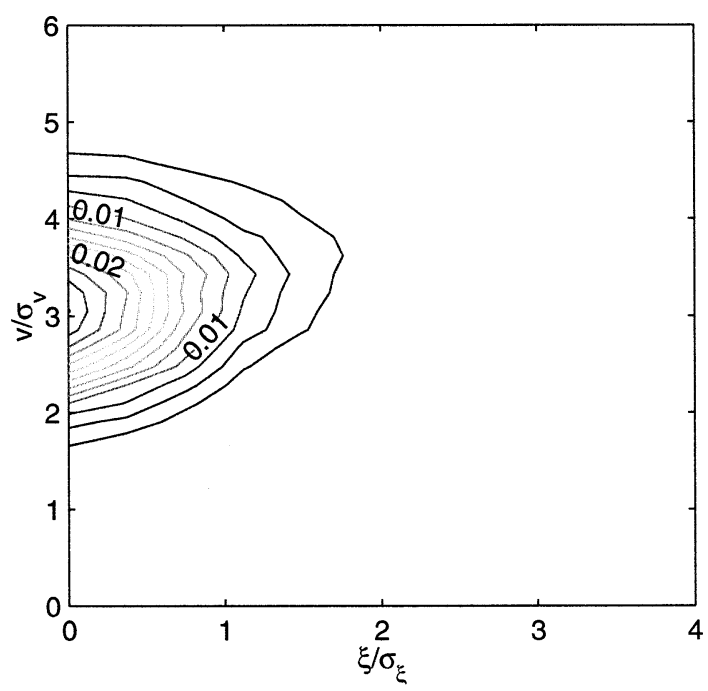

(b)

FIG. 3. Joint PDF of the vorticity $\xi$ and (a) vertically integrated temperature anomaly $T$ and (b) wind speed $v$ for the western North Pacific using the ECMWF reanalysis (ERA-15). In (a) and (b) the contour interval is $2 \times 10^{-4}$. The variables are normalized by their respective standard deviation $\sigma$. The $\sigma_{\xi}, \sigma_{T}$, and $\sigma_{v}$ values are, respectively, 1.3, 2.0, and 2.6 in the western North Pacific basin.

and previous studies (Bengtsson et al. 1995; Vitart et al. 1997), but at the same time they reflect the different properties of the ocean basins in the model. In appendix $\mathrm{C}$, the basin-dependent thresholds obtained for different models and the ECMWF reanalysis are given. The basin-dependent thresholds values do not differ much

TABLE 1. Basin-independent (BInd) and basin-dependent ECHAM4.5 thresholds for vorticity, surface wind speed, and vertically integrated temperature anomaly for each of the ocean basins.

\begin{tabular}{lcccccrrr}
\hline \hline & BInd & SI & AUS & SP & NI & WNP & ENP & ATL \\
\hline$\xi \times 10^{-5}$ & 3.5 & 3.0 & 3.0 & 3.0 & 3.0 & 3.6 & 2.6 & 2.6 \\
$v$ & 15 & 11.4 & 11.8 & 11.2 & 12 & 11.8 & 10.4 & 10.4 \\
$T$ & 3 & 2.1 & 2.0 & 2.1 & 1.7 & 1.9 & 1.9 & 1.9 \\
\hline
\end{tabular}




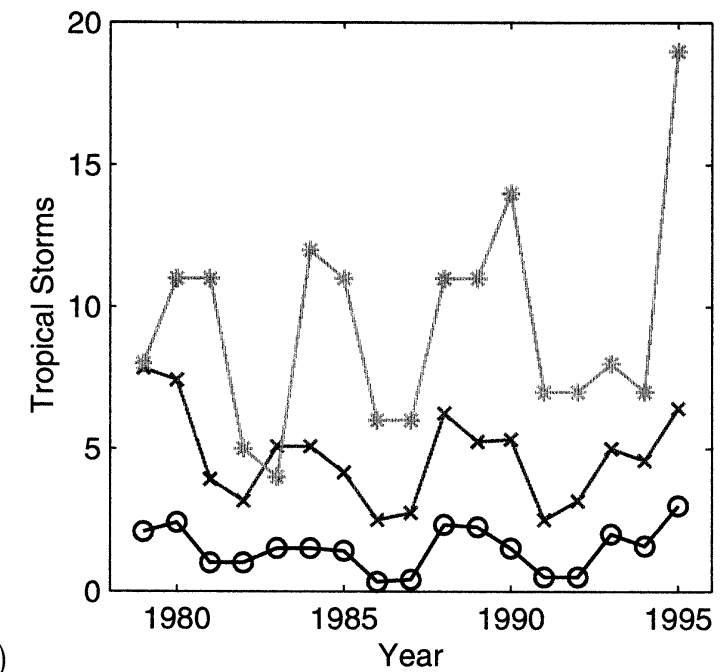

(a)

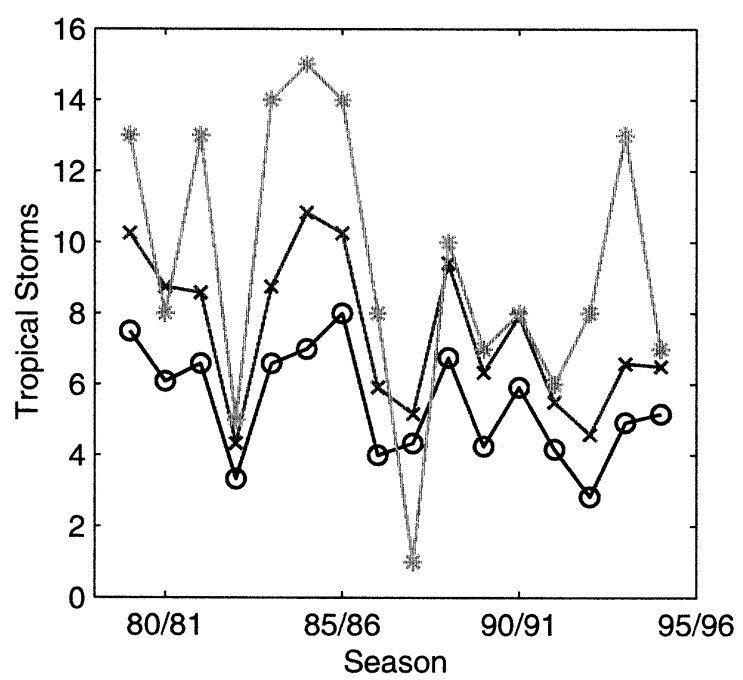

FIG. 4. Ensemble mean number of storms per year detected using basin-independent thresholds $(\bigcirc)$, the basin-dependent thresholds $(\times)$, and observations (*) for (a) the Atlantic and (b) the Australian basins.

among the models. It is interesting to note the impact of using daily average fields versus 6-hourly snapshots in at least one model. This will be discussed further in a future publication.

In Fig. 4 the effect of changing the thresholds from basin-independent to basin-dependent thresholds is shown for the ensemble mean number of storms in the Atlantic and Australian basins. In both cases, the ensemble mean number of storms increases for all years. The four regions in which the basin-dependent algorithm improves the detection significantly, considering all years and ensemble members, are the Atlantic (88\%), eastern Pacific (96\%), south Indian (79\%), and Australian $(63 \%)$. The percentages were calculated using the total number of storms per year in all years and ensemble members. In these basins, the average number of storms becomes closer to observed, although the model bias is not completely corrected. The improvement of the frequency of storms occurred in all the AGCMs analyzed, as the basin-dependent thresholds are also model dependent. Therefore, the detection algorithm managed to obtain better results from AGCMs taking into account the biases of each model.

With the exception of the western North Pacific, the basin-dependent thresholds produce better results than the absolute thresholds. It is important to note that we were especially concerned with the basins such as the Atlantic and eastern North Pacific where few or no storms were being detected, and in these cases, there is good improvement, but the detection method does not produce frequencies near the observed ones. This is not unexpected, because this method does not attempt to determine whether the model is under- or oversimulating storm formation in each basin.

The counting of the tropical storms can be further improved. The present algorithm counts twice a storm that weakens and strengthens again later. This problem especially affects the storm counting in the western North Pacific because of the large number of typhoons per year. In the next section we describe a tracking algorithm that is able to count correctly storms that weaken and strengthen again. How the interannual variability of the number of storms is affected by the basindependent and tracking algorithms is discussed in the next section.

\section{Tracking}

The procedure described in appendix A detects storms that satisfy all our criteria and connects them from one model output time to the next when they are sufficiently close, forming a storm track that can be compared to observed storm tracks. However, the tracks obtained by this procedure are usually quite short. Visual examination of the corresponding vorticity fields shows that the storm structure is visible well before and after the detection criteria are met, suggesting that relaxing detection criteria would produce longer tracks. However, if the detection criteria are simply relaxed uniformly, spurious detections will occur. To avoid spurious detections we only apply the relaxed criteria to points near those that have already met our detection criteria.

We take the first position and time at which the storm meets the detection criteria and then use the low-level vorticity field to track the storm backward and forward in time. First, the vorticity in a $5 \times 5$ gridpoint box is examined around the first position defined previously (based on the minimum sea level pressure). We refer to this box as a vorticity matrix. The location of the maximum value of the vorticity magnitude is found in that matrix and a new vorticity matrix is formed, now of size $3 \times 3$ grid points around the location of the maximum. The centroid of this new vorticity matrix is then 
(a)

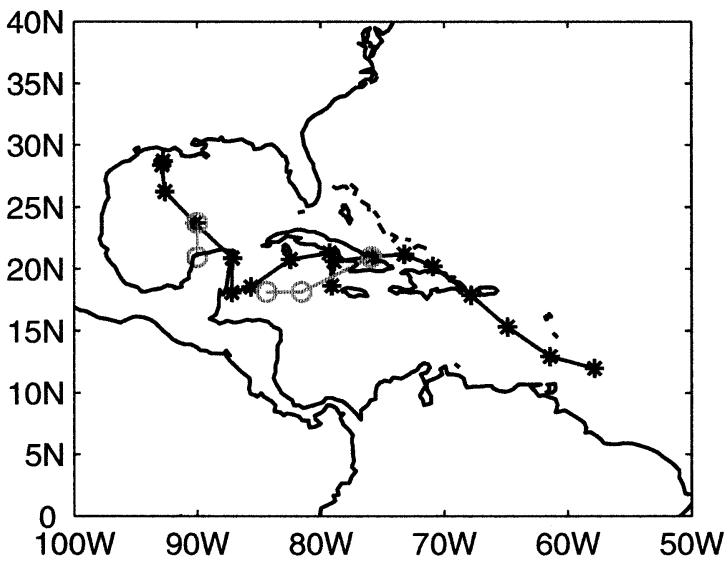

(b)

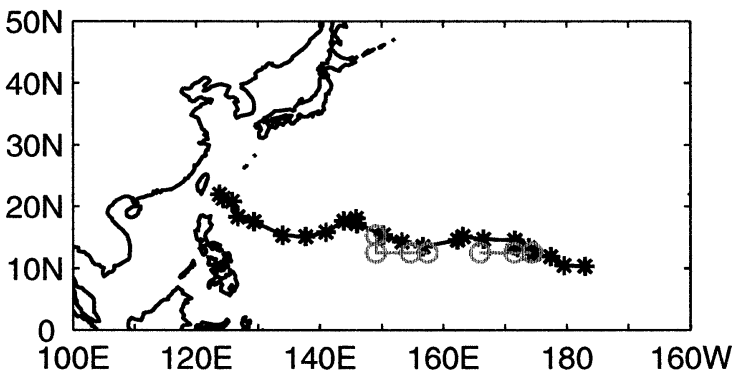

FIG. 5. Tracks of a storm in the (a) Atlantic and (b) western North Pacific using the new tracking $(*)$ routine and the previous one $(\bigcirc)$.

calculated and defined as the initial storm center for that storm.

Using this initial storm center, the storm is then tracked backward and forward in time as follows:

- The grid point nearest the centroid center is obtained.

- A vorticity matrix $(3 \times 3$ grid points $)$ is formed in the next time step around the grid point nearest the centroid center from the previous time step.

- The maximum value of the vorticity magnitude is found in this vorticity matrix and a new vorticity matrix $(3 \times 3$ grid points) is defined around it.

- The position and value of the vorticity centroid of the next time step is calculated in this new vorticity matrix.

- If the absolute value of the vorticity at the centroid at the next time step is larger than the threshold (1.5 $\times 10^{-5} 1 \mathrm{~s}^{-1}$ ), this procedure is repeated. This value was chosen based on trial and error in order to optimize the tracking detection of the model, by looking at the tracks produced using different thresholds and the structures present in the low-level vorticity in the model output field.

This procedure is performed for all storms obtained using the detection algorithm. Then, the tracks obtained are compared and if they are the same, the two storms are counted as a single one. This procedure improves (a)

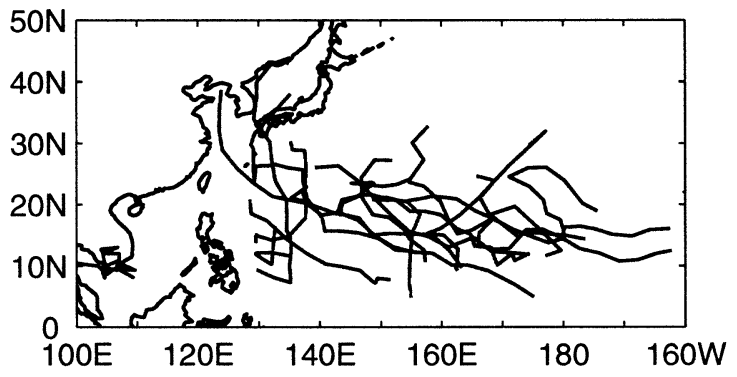

(b)

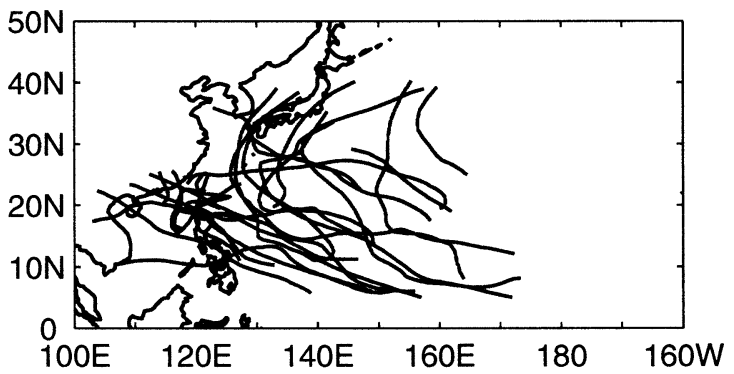

FIG. 6. Tracks of all tropical storms in the western North Pacific during the Jun-Oct 1991 typhoon season for (a) one of the ensemble members using the new tracking routine and (b) observed tropical cyclones.

the tracks of the storms, which are now longer and smoother. The quality of the new tracks has definitely improved toward typical observed tracks. The comparison of the original tracks and the new tracks of one storm in the Atlantic and one in the western North Pacific are shown in Fig. 5. By examining the historical observed tracks of tropical cyclones (see, e.g., Unisys 2002) and comparing them with the model tracks, one finds tropical cyclones with paths similar to model tracks.

Figure 6a shows all the tropical storms in the western North Pacific in one season (June-October, JJASO) for one of the ensemble members. By comparing these tracks with observed tracks in the typhoon season of the same year, shown in Fig. 6b, one sees that though the tracking algorithm improves the original tracks, model biases are not corrected. For example, in the western North Pacific the model tends to form too many storms in the central Pacific and too few in the South China Sea, as compared with observed tracks. Additionally, in the northwest basins of the Atlantic and in the Pacific, model tracks do not reach poleward latitudes as observed and most model tracks do not have the typical observed characteristic curvature near the continents. These model track biases would need to be corrected for application to landfall studies.

The counting of the storms is improved since storms that were counted twice or thrice are now correctly counted as a single storm. The tracking algorithm is then essential for a physically correct counting of the storms. The procedure additionally makes the counting 
TABLE 2. Ensemble average (12 members) number of storms in 17 yr (1979-95) using the basin-independent thresholds, the basin-dependent thresholds with the new tracking algorithm, and observed values.

\begin{tabular}{lrrrrrrr}
\hline \hline \multicolumn{1}{c}{ Type } & SI & AUS & SP & NI & WNP & ENP & ATL \\
\hline Basin independent & 6.0 & 5.4 & 4.1 & 12.7 & 30.1 & 1.0 & 1.5 \\
Basin and tracking & 7.8 & 6.0 & 4.6 & 7.5 & 29.4 & 3.3 & 3.1 \\
Observed & 12.5 & 9.2 & 6.1 & 4.9 & 27.7 & 17.5 & 9.3 \\
\hline
\end{tabular}

of the number of storms more reliable. Both cases shown in Fig. 5 were counted initially as more than one storm, but using the tracking algorithm on these storms led us to count each of them correctly as one single storm. The effect of the tracking algorithm on the counting is especially important in the western North Pacific because of the high number of storms occuring in that basin. Table 2 shows the average number of storms in each basin initially and after applying the detection and tracking algorithms. The average number of storms becomes more similar to the observed number in all basins in the latter case. The climatology of the storms in the different basins is improved using both the new thresholds and the new tracking procedure, as can be seen in Fig. 7, which shows the annual cycle for the model ensemble members in the South Pacific and in the Atlantic, using the previous methodology and the one described here.

The interannual variability of the number of storms is affected both by using the basin-dependent thresholds and the tracking algorithm. Tables 3 and 4 show the correlations and the root-mean-square errors of the number of tropical storms using the basin-independent thresholds and the basin-dependent thresholds with the tracking algorithm in comparison with observations. The changes in the correlations are not significant, according to the Fisher test. However, before applying our basin-dependent and tracking algorithms, only two (Australian and Atlantic basins) out of seven basins have significant correlations (95\% confidence level); these basins continue to have significant correlations and an additional one (eastern North Pacific) has a significant correlation. Therefore, using correlation as our measure, the interannual variability is improved in one basin and remains significant in the other two.

Using the root-mean-square error to look at the interannual variability, only in the south Indian and South Pacific basins is the root-mean-square error larger after applying both the basin-dependent and tracking algorithm than it had been originally; in the other five basins there is an improvement in the value of the root-mean-

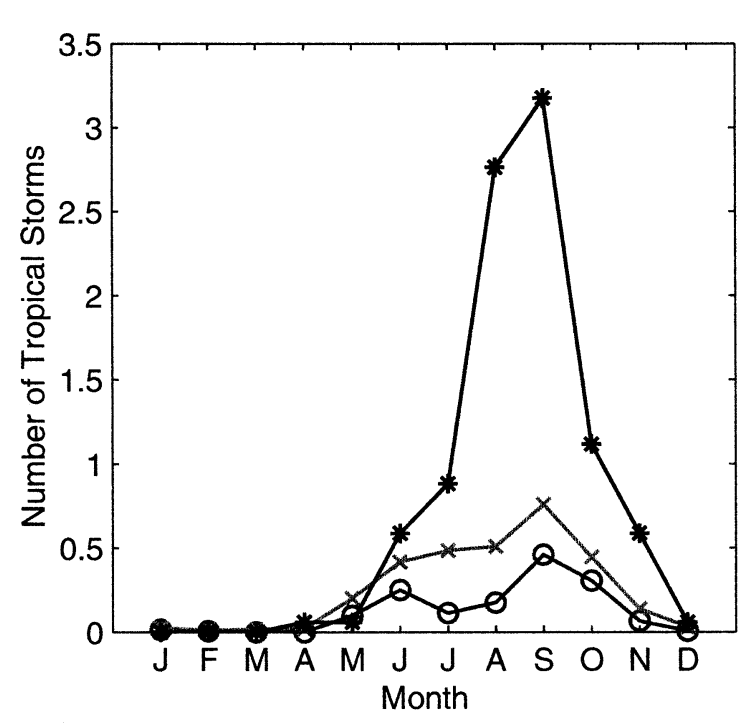

(a)

(b)

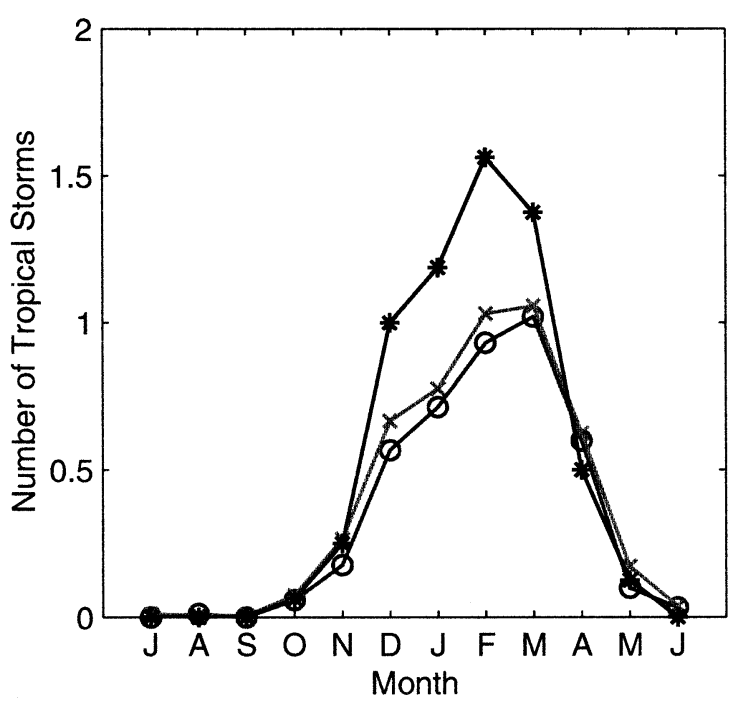

FIG. 7. Annual cycle of tropical storms in the (a) Atlantic and (b) South Pacific using the basin-dependent thresholds with the new tracking routine $(X)$ and the basin-independent thresholds with the previous tracking method $(\bigcirc)$. The observed annual cycle $(*)$ is also shown.

square error. In the two basins where the root-meansquare error is larger than when using basin-dependent thresholds, the correlations of the number of observed and ensemble mean number of storms are not significant. In summary, by using the detection and tracking algorithm there is a slight improvement in the interannual variability of the model globally.

TABLE 3. Correlation of the observed number of tropical storms with the ensemble average number of storms using the basin-independent thresholds and the new thresholds with the new tracking algorithm. Boldface correlation values are significant at $95 \%$ confidence level.

\begin{tabular}{ccccccc}
\hline \hline Type & SI & AUS & SP & NI & WNP & ENP \\
\hline Basin independent & 0.058 & $\mathbf{0 . 7 2 6}$ & 0.265 & -0.318 & 0.162 & 0.402 \\
Basin and tracking & -0.162 & $\mathbf{0 . 7 2 2}$ & 0.177 & -0.241 & 0.222 & $\mathbf{0 . 5 5 4}$ \\
\hline
\end{tabular}


TABLE 4. Root-mean-square error between the observed number of tropical storms and the ensemble average number of storms using the basin-independent thresholds and the basin-dependent thresholds with the new tracking algorithm.

\begin{tabular}{cccccccc}
\hline \hline Type & SI & AUS & SP & NI & WNP & ENP & ATL \\
\hline Basin independent & 2.62 & 2.92 & 3.07 & 3.32 & 5.57 & 4.09 & 3.21 \\
Basin and tracking & 2.84 & 2.87 & 3.23 & 2.77 & 4.76 & 3.81 & 3.05 \\
\hline
\end{tabular}

Similar results were obtained when applying the tracking algorithm to other AGCMs. This tracking algorithm was also used successfully for tropical cyclones in the Indian Ocean generated by a regional model (the Regional Climate Model, version 2; RegCM2; Giorgi et al. 1993) using different boundary domains (Landmann et al. 2002).

In the case of the ECMWF reanalysis, the climatology of the number of storms is improved by using the detection and tracking algorithms, and the mean number of storms is improved in all basins. It is important to note that the ECMWF does not include "bogus observations" of observed tropical cyclones, which are widely used in several other analyses products (see Walsh 1997 and references therein).

The impact of the detection and tracking schemes on the interannual variability of number of storms in the ECMWF reanalysis was analyzed using correlations and the root-mean-square error in comparison with the observed number of storms. The root-mean-square error diminishes in all the ocean basins. Changes of the correlation values were significant in only one ocean basin and in this case the correlation became significant. The interannual variability of the number of storms in the ECMWF reanalysis then improved by applying the algorithms described here.

\section{Conclusions}

Algorithms for detection and tracking of tropical cyclones in AGCMs were presented and applied to an ensemble of AGCM simulations. These algorithms use basin-dependent statistics to define detection criteria thresholds and a centroid vorticity calculation to track the cyclone in time. The usage of these algorithms on average improves both the climatology and the tracks of tropical cyclones and therefore improves the possible use of AGCMs in forecasting seasonal cyclone frequency. Significant biases still remain and need to be addressed through increased resolution and changes in model physics. Although this work has presented results from a single model, the algorithms have been applied successfully to several AGCMs.

Seasonal forecasts of tropical storm frequencies based on the application of these detection and tracking algorithms applied to AGCM forecasts are presently being evaluated and will be reported on in future work.
Acknowledgments. The authors thank the Max Planck Institute for Meteorology (Hamburg, Germany) for making their model ECHAM accessible to IRI. We thank Dr. Michael K. Tippett (IRI) for his comments on an earlier version of this paper, Dr. Anthony Barnston (IRI) for his insight on statistical issues, and two anonymous reviewers for helpful comments.

\section{APPENDIX A}

\section{Detection Algorithm}

1) The $850-\mathrm{hPa}$ relative vorticity exceeds the vorticity threshold. In the Southern Hemisphere a negative threshold is used.

2) The maximum surface wind speed in a centered 7 $\times 7$ box exceeds the wind speed threshold.

3) The sea level pressure is the minimum in a centered $7 \times 7$ box.

4) The temperature anomaly averaged over the $7 \times 7$ box and three pressure levels (300, 500, and 700 $\mathrm{hPa}$ ) exceeds the temperature anomaly threshold.

5) The local temperature anomaly averaged over the 7 $\times 7$ box is positive at all three pressure levels (300, 500 , and $700 \mathrm{hPa}$ ).

6) The local temperature anomaly, averaged over the 7 $\times 7$ box, at $300 \mathrm{hPa}$ is greater than at $850 \mathrm{hPa}$.

7) The mean speed averaged over a $7 \times 7$ grid box is larger at $850 \mathrm{hPa}$ than at $300 \mathrm{hPa}$.

8) The grid points representing the center of storms that obeyed all the criteria above are connected if they are less than a certain distance from the center of the previous time step analyzed. ${ }^{\mathrm{A} 1}$ This distance is defined by the frequency of the output of the model. For 6-hourly outputs, we use two grid points $\left(5.6^{\circ}\right)$ in longitude and/or latitude, while for daily output, three grid points is the maximum distance $\left(8.5^{\circ}\right)$ possible. ${ }^{\mathrm{A} 2}$

9) If the storm lasts at least 2 days (1.5 in the case of 6-hourly output), it is identified as a model tropical storm.

\section{APPENDIX B}

\section{Construction of the PDFs}

The PDFs and statistical properties of the chosen variables (vorticity, surface wind speed, and vertically in-

\footnotetext{
${ }^{\text {A1 }}$ All the grid points that obey the previous criteria are connected as one storm. This part of the algorithm does not distinguish among several possibilities for tropical tracks; this is done in the tracking algorithm described in section 4 .

A2 This maximum distance is only used in the detection algorithm; this restriction in not used in the tracking algorithm described in section 3 . None of the many storms in the models we analyzed covered a distance longer than that. However, this is possible for observed tropical cyclones in the Atlantic and eastern Pacific, such as happened with Hurricane Floyd in 1999.
} 
tegrated anomalous temperature) are calculated in each basin using only the values during the tropical cyclone peak season of that basin: June-October for the western North Pacific, eastern North Pacific, and Atlantic; December-April for south Indian Ocean, Australian basin, and South Pacific Ocean; and May, June, September, October, and November for the north Indian Ocean. The points must satisfy criteria 3,5 , and 6 . The PDFs were obtained with the following procedure:

- Calculate the daily vertically integrated temperature, the sum of the temperature at 700, 500, and $300 \mathrm{hPa}$ in each grid point.

- A local average daily vertically integrated temperature is calculated in a square, $7 \times 7$ grid points, centered at the grid point of interest.

- The anomalous vertically integrated daily temperature in the grid point at the center of the square is calculated as the difference between the daily vertically integrated temperature in that grid point and the local average daily verticaly integrated temperature around it.

- The anomalous daily temperature for the levels 850 , 700,500 , and $300 \mathrm{hPa}$ is calculated, by analogy to the anomalous vertically integrated temperature.

- The difference of the temperature anomalies at 850 and $300 \mathrm{hPa}$ is calculated. The temperature anomaly at $850 \mathrm{hPa}$ has to be positive and smaller than the temperature anomaly at $300 \mathrm{hPa}$.

- The signs of the temperature anomalies at 700, 500, and $300 \mathrm{hPa}$ are compared.

- In order to be defined as having a warm core, two different criteria must be satisfied: the sign of the temperature anomalies in all three levels (700, 500, and $300 \mathrm{hPa}$ ) must be the same, and the temperature anomaly at $850 \mathrm{hPa}$ must be smaller than at $300 \mathrm{hPa}$. If these two criteria are not satisfied, that grid point is excluded from our temperature anomaly statistics of the probability distribution functions and from the temperature anomalies statistics.

- The average and the standard deviation of the vorticity at $850 \mathrm{hPa}$, surface winds, and vertically integrated temperature (only at the grid points not excluded by the previous criterion) are calculated for the time period of the integration (1979-95) using the 13 ensemble members in each of the ocean basins.

- The sea level pressure value is then examined in a box of $7 \times 7$ grid points around the grid point that passed all previous criteria. If this grid point is also a local minimum of sea level pressure, it is used to construct our PDFs.

- We calculated one PDF for each ocean basin using the selected grid points of the vertically integrated temperature anomaly, low-level vorticity, and surface wind speed. This is done for each of the basins, using all the years of the integration and all the ensemble members to construct the basin-dependent PDFs.

- The vorticity at $850 \mathrm{hPa}$ is then examined for the grid points that satisfy the warm core criteria and the vorticity value is binned in previously chosen vorticity values. If the vorticity value is in one of the bins of vorticity values chosen, the sea level pressure value is examined in a box of $7 \times 7$ grid points around it. In case this is a local minimum of the sea level pressure, the values of the vertically integrated temperature anomaly and of the surface wind speed in that box are also examined and a probability distribution function is constructed for all the basins.

\section{APPENDIX C}

\section{Basin-Dependent Thresholds in Different AGCMs}

We applied the detection and tracking algorithms described in this paper in different AGCMs and the ECMWF reanalysis (Gibson et al. 1997). Besides the integration of the ECHAM4.5 model described, two other integrations of the ECHAM4.5 model were analyzed. Thresholds for a previous version of this model, ECHAM3 (Model User Support Group 1992), are also shown, as well as for the NSIPP (Suarez and Takacs 1995) model. The time periods and types of output are given in Table $\mathrm{C} 1$, together with the name used here to distinguish among the different ECHAM4.5 integrations.

Different basin-dependent thresholds were obtained in each model, as shown in Table C2. The model with the highest thresholds values for the surface wind speed was NSIPP, while the vorticity low-level thresholds were very similar to the other models. The temperature thresholds were the ones that differed the least among the models. It is interesting to note that the ECMWF reanalysis thresholds do not differ much from those of the other AGCMs.

TABLE C1. Time periods and type of output used in the models and reanalysis.

\begin{tabular}{llll}
\hline \hline \multicolumn{1}{c}{ Model } & \multicolumn{1}{c}{ Period } & \multicolumn{1}{c}{ Output } & Name \\
ECHAM4.5 & $1979-95$ & Daily snapshots & ECHAM4.5 \\
ECHAM4.5 & $1950-2000$ & Daily averages & ECHAM4.5DA \\
ECHAM4.5 & $1950-2000$ & Six-hourly snapshots & ECHAM4.5SH \\
ECHAM3 & $1949-2000$ & Six-hourly snapshots & ECHAM3 \\
NSIPP & $1961-2000$ & Daily snapshots & ECIPP \\
ECMWF reanalysis & $1979-93$ & Six-hourly snapshots & ECMF \\
\hline
\end{tabular}


TABLE C2. Basin-dependent thresholds of different AGCMs and ECMWF reanalysis.

\begin{tabular}{|c|c|c|c|c|c|c|c|c|}
\hline Model & Variable & SI & AUS & SP & NI & WNP & ENP & ATL \\
\hline ECHAM4.5 & $\xi=10^{-5}$ & 3.0 & 3.0 & 3.0 & 3.0 & 3.6 & 2.6 & 2.6 \\
\hline ECHAM4.5 & $v$ & 11.4 & 11.8 & 11.2 & 12 & 11.8 & 10.4 & 10.4 \\
\hline ECHAM4.5 & $T$ & 2.1 & 2.0 & 2.1 & 1.7 & 1.9 & 1.9 & 1.9 \\
\hline ECHAM4.5DA & $\xi \times 10^{-5}$ & 2.8 & 3.0 & 2.8 & 3.0 & 3.4 & 2.4 & 2.4 \\
\hline ECHAM4.5DA & $v$ & 11.4 & 11.8 & 11.2 & 12 & 11.8 & 10.4 & 10.4 \\
\hline ECHAM4.5DA & $T$ & 1.9 & 1.8 & 1.9 & 1.4 & 1.8 & 1.8 & 1.8 \\
\hline ECHAM4.5SH & $\xi \times 10^{-5}$ & 2.8 & 3.0 & 3.0 & 3.0 & 3.4 & 2.6 & 2.6 \\
\hline ECHAM4.5SH & $v$ & 11.6 & 12 & 11.4 & 12.2 & 1 & 10.6 & 10.6 \\
\hline ECHAM4.5SH & $T$ & 2.0 & 2.0 & 2.1 & 1.5 & 1.9 & 1.9 & 1.9 \\
\hline ECHAM3 & $\xi \times 10^{-5}$ & 2.6 & 2.6 & 2.2 & 2.4 & 2.8 & 2.2 & 2.6 \\
\hline ECHAM3 & $v$ & 10.6 & 10.6 & 9.8 & 10.0 & 10.4 & 9.4 & 9.8 \\
\hline ECHAM3 & $T$ & 2.1 & 2.1 & 1.8 & 1.7 & 1.8 & 2.2 & 1.9 \\
\hline NSIPP & $\xi \times 10^{-5}$ & 2.6 & 2.8 & 2.4 & 3.4 & 2.6 & 2.2 & 2.4 \\
\hline NSIPP & $v$ & 13.2 & 13.0 & 12.8 & 13.6 & 13.4 & 12.4 & 12.4 \\
\hline NSIPP & $T$ & 1.9 & 1.8 & 1.9 & 1.9 & 1.9 & 2.0 & 1.8 \\
\hline ECMWF & $\xi \times 10^{-5}$ & 2.4 & 2.6 & 2.4 & 2.6 & 2.6 & 2.0 & 2.0 \\
\hline ECMWF & $v$ & 10.8 & 11.0 & 10.2 & 11.4 & 10.6 & 9.8 & 10.0 \\
\hline ECMWF & $T$ & 2.1 & 2.2 & 2.5 & 1.5 & 2.0 & 1.9 & 1.9 \\
\hline
\end{tabular}

\section{REFERENCES}

Atmospheric Model Intercomparison Project II, cited 1997: AMIP II sea surface temperature and sea ice concentration observations. [Available online at http://www.pcmdi.llnl.gov/amip/ AMIP2EXPDSN/BCS_OBS/amip2_bcs.htm.]

Bengtsson, L., 2001: Hurricane threats. Science, 293, 440-441.

— H. Böttger, and M. Kanamitsu, 1982: Simulation of hurricanetype vortices in a general circulation model. Tellus, 34, 440457.

_, M. Botzet, and M. Esh, 1995: Hurricane-type vortices in a general circulation model. Tellus, 47A, 175-196.

Broccoli, A. J., and S. Manabe, 1990: Can existing climate models be used to study anthropogenic changes in tropical cyclone climate? Geophys. Res. Lett., 17, 1917-1920.

Camargo, S. J., and A. H. Sobel, 2002: Western North Pacific "tropical cyclogenesis" in an atmospheric general circulation model. Preprints, 25th Conf. on Hurricanes and Tropical Metereology, San Diego, CA, Amer. Meteor. Soc., 53-54.

Chan, J. C. L., J. E. Shi, and C. M. Lam, 1998: Seasonal forecasting of tropical cyclone activity over the western North Pacific and the South China Sea. Wea. Forecasting, 13, 997-1004.

CPC, cited 2002: NOAA: 2002 Atlantic hurricane outlook. [Available online at http://www.cpc.ncep.noaa.gov/products/outlooks/hurricane.html.]

Gibson, J. K., P. Källberg, S. Uppala, A. Hernandez, A. Nomura, and E. Serrano, 1997: ERA description. ECMWF Re-Analysis Project Report Series, No. 1, European Centre for Medium-Range Weather Forecasts, Reading, United Kingdom, 72 pp.

Giorgi, F., M. R. Marinucci, and G. T. Bates, 1993: Development of a second-generation regional climate model $(\operatorname{Regcm} 2)$. Part I: Boundary-layer and radiative transfer processes. Mon. Wea. Rev., 121, 2794-2813.

Goddard, L., S. J. Mason, S. E. Zebiak, C. F. Ropelewski, R. E. Basher, and M. A. Cane, 2001: Current approaches to seasonal to interannual climate predictions. Int. J. Climatol., 21, 1111-1152.

Gray, W. M., C. W. Landsea, P. W. Mielke Jr., and K. J. Berry, 1993 Predicting Atlantic basin seasonal tropical cyclone activity by 1 August. Wea. Forecasting, 8, 73-86.

$\_, \ldots, \ldots$, and ——, 1994: Predicting Atlantic basin seasonal tropical cyclone activity by 1 June. Wea. Forecasting, 9, 103115.

Haarsma, R. J., J. F. B. Mitchell, and C. A. Senior, 1993: Tropical disturbances in a GCM. Climate Dyn., 8, 247-257.

Hodges, K. I., 1994: A general method for tracking analysis and its application to meteorological data. Mon. Wea. Rev., 122, 2573 2586.

Krishnamurti, T. N., 1988: Some recent results on numerical weather prediction over the tropics. Aust. Meteor. Mag., 36, 141-170.

—_, D. Oosterhof, and N. Dignon, 1989: Hurricane prediction with a high resolution global model. Mon. Wea. Rev., 117, 631-669.

Landmann, W. A., A. Seth, and S. J. Camargo, 2002: The effect of regional climate model domain choice on the simulation of tropical cyclone-like vortices in the southwestern Indian ocean. IRI Tech. Rep. 02-06, International Research Institute for Climate Prediction, Palisades, NY, 30 pp.

Landsea, C. W., W. M. Gray, P. W. Mielke Jr., and K. J. Berry, 1994: Seasonal forecasting of Atlantic hurricane activity. Weather, 49, 273-284.

Manabe, S., J. L. Holloway, and H. M. Stone, 1970: Tropical circulation in a time integration of a global model of the atmosphere. J. Atmos. Sci., 27, 580-613.

Mason, S. J., L. Goddard, N. E. Graham, E. Yulaeva, L. Q. Sun, and P. A. Arkin, 1999: The IRI seasonal climate prediction system and the 1997/98 El Niño event. Bull. Amer. Meteor. Soc., 80, $1853-1873$.

Model User Support Group, 1992: ECHAM3 - atmospheric general circulation model. Tech. Rep. 6, Das Deutshes Klimarechnenzentrum, Hamburg, Germany, 184 pp.

Murray, R. J., and I. Simmonds, 1991: A numerical scheme for tracking cyclone centres from digital data, Part I: Development and operation of the scheme. Aust. Meteor. Mag., 39, 155-166.

Nguyen, K. C., and K. J. E. Walsh, 2001: Interannual, decadal, and transient greenhouse simulation of tropical cyclone-like vortices in a regional climate model of the South Pacific. J. Climate, 14, 3043-3054.

Nicholls, N., 1992: Recent performance of a method for forecasting Australian seasonal tropical cyclone activity. Aust. Meteor. Mag., 40, 105-110.

Roeckner, E., and Coauthors, 1996: The atmospheric general circulation model ECHAM-4: Model description and simulation of present-day climate. Tech. Rep. 218, Max-Planck Institute for Meteorology, Hamburg, Germany, 90 pp.

Ryan, B. F., I. G. Watterson, and J. L. Evans, 1992: Tropical cyclone frequencies inferred from Gray's yearly genesis parameter: Validation of GCM tropical climate. Geophys. Res. Lett., 19, 18311834.

Serrano, E., 1997: Tropical cyclones. ECMWF Re-Analysis Project Report Series, No. 5, European Centre for Medium-Range Weather Forecasts, Reading, United Kingdom, 30 pp. 
Suarez, M. J., and L. L. Takacs, 1995: Documentation of the Aries/ GEOS dynamical core, version 2. NASA Tech. Memo. 104606, Vol 6., Goddard Space Flight Center, Greenbelt, MD, 58 pp.

Thorncroft, C., and I. Pytharoulis, 2001: A dynamical approach to seasonal prediction of Atlantic tropical cyclone activity. Wea. Forecasting, 16, 725-734.

Treut, H. L., and E. Kalnay, 1990: Comparison of observed and simulated cyclone frequency distribution as determined by an objective method. Atmósfera, 3, 57-71.

Tsutsui, J. L., and A. Kasahara, 1996: Simulated tropical cyclones using the National Center for Atmospheric Research community climate model. J. Geophys. Res., 101, 15 013-15 032.

UCL, cited 2002: Seasonal forecasts. [Available online at http:// forecast.mssl.ucl.ac.uk/forecast.html.]

Unisys, cited 2002: Unisys weather hurricane tropical data. [Available online at http://weather.unisys.com/hurricane/.]

Vitart, F., 1998: Tropical storm interannual and interdecadal variability in an ensemble of GCM integrations. Ph.D. dissertation, Princeton University, $387 \mathrm{pp}$.
- , and T. N. Stockdale, 2001: Seasonal forecasting of tropical storms using coupled GCM integrations. Mon. Wea. Rev., 129, 2521-2537.

_ - J. L. Anderson, and W. F. Stern, 1997: Simulation of interannual variability of tropical storm frequency in an ensemble of GCM integrations. J. Climate, 10, 745-760.

Walsh, K., 1997: Objective detection of tropical cyclones in highresolution analyses. Mon. Wea. Rev., 125, 1767-1779.

Watterson, I. G., J. L. Evans, and B. F. Ryan, 1995: Seasonal and interannual variability of tropical cyclogenesis: Diagnostics from large-scale fields. J. Climate, 8, 3042-3066.

Williamson, D. L., 1981: Storm track representation and verification. Tellus, 33, 513-530

Wu, G., and N. C. Lau, 1992: A GCM simulation of the relationship between tropical storm formation and ENSO. Mon. Wea. Rev., 120, 958-977.

Zolina, O., and S. K. Gulev, 2002: Improving the accuracy of mapping cyclone numbers and frequencies. Mon. Wea. Rev., 130, 748 759. 